\title{
La responsabilidad por producto defectuoso en el derecho colombiano*
}

\author{
Liability for defective product in the Colombian law \\ Recibido: 19 de mayo de 2014 - Revisado: 04 de septiembre de 2014 - Aceptado: 06 de noviembre de 2014 \\ Juan Carlos Villalba Cuéllar
}

\begin{abstract}
Resumen
El régimen de responsabilidad por productos defectuosos es un resultado de los desafíos que la industrialización impuso a la responsabilidad civil clásica. Este artículo tiene como objetivo trazar las características de esta responsabilidad en la ley 1480 de 2011 colombiana, tomando elementos del derecho comparado para explicar sus alcances así como los antecedentes jurisprudenciales sobre la materia en Colombia.
\end{abstract}

\section{Palabras clave}

Responsabilidad, seguridad, consumidor, producto defectuoso.

\begin{abstract}
The system of liability for defective products is a result of industrialization challenges imposed to the classical liability. This article aims to outline the characteristics of this liability according to the recently issued Law 1480 of 2011 in the Colombian context, taking elements from comparative law to explain its scope and the legal background on the subject in Colombia.
\end{abstract}

\section{Key words}

Liability, security, consumer, defective product.

\footnotetext{
* Este artículo de reflexión pertenece a la investigación denominada " $\mathrm{La}$ responsabilidad del productor en Colombia", del grupo Derecho Privado, línea de investigación derecho económico y de los negocios. Se adelanta en el Centro de Investigaciones Jurídicas, Políticas y Sociales de la Facultad de Derecho de la Universidad Militar Nueva Granada, Bogotá, Colombia.

** Abogado, docente e investigador, miembro de la línea de investigación en derecho económico y de los negocios, Grupo de Investigación Derecho Privado del Centro de Investigaciones de la Facultad de Derecho de la Universidad Militar Nueva Granada. Magíster LLM en Derecho Francés, Europeo e Internacional de Negocios de la Université Panthéon-Assas Paris II y del Instituto de Derecho Comparado de París (Francia). Especialista en docencia universitaria. Correo electrónico:

juan.villalba@unimilitar.edu.co
} 


\section{Introducción}

La responsabilidad civil es una fuente de las obligaciones que tuvo un desarrollo importante a partir de la industrialización de las relaciones comerciales, en especial con la aparición de las máquinas y la consolidación de la producción en masa. Nos encontramos en la actualidad en el contexto de la denominada por Beck (2006), sociedad del riesgo, en la cual la producción social de la riqueza se acompaña de forma sistemática de la producción social de riesgos, y en la que es sustancial el problema de la definición y reparto de los riesgos generados de manera científico-técnica. Para este autor, el concepto de "sociedad industrial o de clases" giraba en torno a la cuestión de cómo se puede distribuir la riqueza creada socialmente de un modo desigual y al mismo tiempo "legítimo".

El nuevo paradigma de la sociedad del riesgo halla su núcleo en la solución del problema de cómo se puede evitar, minimizar, dramatizar y canalizar los riesgos y peligros que se han dado regularmente en el proceso avanzado de modernización, para reducirlos de tal suerte que no obstaculicen ese proceso ni sobrepasen los límites de lo "soportable" (pp. 28-29). Es bien conocido y resaltado por la doctrina, el cambio que implicó pasar en los ordenamientos jurídicos derivados del derecho continental europeo del régimen de responsabilidad subjetiva (con culpa), a grados más exigentes de responsabilidad que tuvieron como antecedente la teoría de los riesgos, para dar lugar a la responsabilidad objetiva (responsabilidad sin culpa).

En la era del fordismo surgió el desafío de saber si el daño ocasionado por una máquina debía cobijarse con el manto de la responsabilidad contractual o si por el contrario, debía extenderse su cobertura a todos los miembros de la cadena de valor. Es así como en el ámbito del derecho anglosajón floreció la teoría de la responsabilidad del productor, la cual adquirió poco a poco unos matices particulares, de tal forma que hoy en día se considera una especie de responsabilidad que tiene fisonomía propia. A causa del rápido proceso de industrialización, este fenómeno se vivió primero en los países desarrollados como los Estados Unidos y en el ámbito de Europa occidental, y en los últimos años se ha ido reglamentando el tema en la mayoría de ordenamientos jurídicos del mundo.

La preocupación por avanzar en la legislación de esta materia a través de un sistema de responsabilidad apropiado, fue motivada también por casos tristemente célebres, como el de la talidomida en Alemania y otras naciones a mediados del siglo pasado, o aquel del aceite de colza en España, con miles de víctimas en uno $\mathrm{y}$ otro caso, las cuales pusieron de manifiesto los efectos sociales negativos que puede tener la comercialización de productos defectuosos en el mercado. En otros incidentes como el de Ford Pinto, en los Estados Unidos, se evidenció además la irracionalidad y desinterés con que pueden actuar a veces los productores movidos por la relación costo-beneficio. Se puede agregar que la responsabilidad del productor se liga al auge y avance de las normas de protección al consumidor y en el ámbito de la regulación de este derecho se ha desarrollado el tema. Se dice que el régimen tradicional de la responsabilidad civil encuentra nuevos matices en el esquema de la responsabilidad por productos defectuosos, fundados sin duda alguna en el afán por proteger a las víctimas, a los débiles en las relaciones jurídicas (Hinestrosa, 2003, p. 342).

En Colombia es de reciente aparición, y a pesar de que el asunto estaba implícitamente regulado en el antiguo decreto 3466 de 1982, durante muchos años no tuvo un progreso evidente más allá de algunos precedentes jurisprudenciales y doctrinales que se pondrán de manifiesto en este escrito. El objetivo principal de este documento es medir las repercusiones de la normativa de la materia en la ley 1480 de 2011. Para tal fin se hará en primer lugar, una breve revisión de su historia y se pasará 
luego a estudiar el ámbito de aplicación de este "nuevo" régimen de responsabilidad, desde el punto de vista sustancial, aparte en el cual nos detendremos en el alcance de las definiciones de la ley colombiana sobre el tema, en específico las nociones de producto defectuoso, seguridad, deber de seguridad, producto, y las clases de defectos que abarca la disposición. Acto seguido se propone revisar las características de la responsabilidad por producto defectuoso, los requisitos para que se configure y las causales de exoneración planteadas por la regulación en el ámbito nacional. Por tratarse de una cuestión ampliamente tratada en el derecho comparado, en la redacción de este artículo se hace un esfuerzo en la citación de doctrina extranjera.

El presente artículo es de reflexión y expone una perspectiva analítica sobre el ordenamiento del tema en la ley 1480 de 2011. Para su redacción se utilizó el método hermenéutico-analítico, a partir del estudio de la norma en el contexto legal colombiano, con herramientas de método comparativo e histórico, como quiera que se empleó como referente la legislación y doctrina extranjera y los pocos avances jurisprudenciales y doctrinales que existían en Colombia sobre el asunto.

\section{Origen y delimitación conceptual de la responsabilidad por productos defectuosos}

\section{El origen de la responsabilidad por productos defectuosos.}

La tesis de la responsabilidad por productos defectuosos se afianzó en el contexto del derecho anglosajón, en el cual los jueces encontraron el desafío de determinar en quién recaía la responsabilidad, pasando de la doctrina contractualista tradicional denominada privity of contract-que se basa en el derecho continental europeo en el principio caveat emptor y en la relatividad de los actos jurídicos- a una especie de responsabilidad objetiva (strict liability).
Los jueces ingleses en los primeros casos radicaron la responsabilidad en aquel comerciante que tuviese un vínculo contractual con la víctima, así, cita la doctrina que en el caso Winterbottom vs. Wright (1842) un juez inglés aplicó en estricto la responsabilidad contractual y no quiso llevar la responsabilidad al escenario extracontractual (torts), con lo que benefició claramente al productor (Woolcott, 2007a, p. 127). Por su parte, Munar (2013) estima que los empresarios tenían así en el ordenamiento jurídico un factor, que además de minimizar costos, los hacía inalcanzables para el consumidor a la hora de indemnizar los perjuicios ocasionados por los defectos de sus productos (p. 177).

Comenta Coleman (2010) que la regla de la asignación del riesgo por medio del contrato generaba un dilema: lo que es bueno para el productor no lo era para la sociedad (p. 407). En ese estado de cosas, los jueces norteamericanos iniciaron el camino hacia la aceptación de la responsabilidad del productor. Años más tarde, el caso MacPherson vs. Buick Motor (1916) marcó una línea jurisprudencial importante para el abandono de la doctrina anterior, en el mismo, el juez condenó al productor del vehículo por un daño ocasionado por una rueda al considerar el concepto de "peligro inherente a la cosa" (inherently dangerous), a pesar de que este no tenía un nexo contractual con la víctima.

La regla se aplicaba si se daba por parte del productor una falta al reasonable care en el proceso de producción, y la prueba de esta diligencia recaía en cabeza del productor por tener este el control del proceso de producción y distribución. Se pasó entonces a un sistema de responsabilidad del productor frente a terceros si el defecto era imputable a su negligencia (Coderch, Piñeiro, \& Rubí, 2003, p.6). Con el caso Mazzetti vs. Armour \& Co. de 1913 se creó además el concepto de garantía implícita (implied warranty) que se aplicaba también a terceros que no guardaran conexión contractualmente al productor. Empero, el caso 
Escola vs. Coca Cola Bottling Co. of Fresno (1944) significó el auge de la teoría de la responsabilidad por producto defectuoso strict product liability, y así se prescindió de la teoría de la negligencia (negligence) para avanzar en el reconocimiento de una responsabilidad objetiva pura (Munar, 2013, p. 182).

En 1960 el casoHenningsenvs. Bloomfield Motors Inc. determinó la superación de la teoría contractual, a partir de ella se creó la garantía implícita de comerciabilidad declarando su aplicación a terceros que no hayan comprado el producto y admitiendo su pertinencia para todo tipo de productos. Esta jurisprudencia se complementaría con el caso Greenman vs. Yuba Power Products Inc. en 1963. En 1965 se expidió la Restatement of torts, sección 402 A relativa a los daños por producto defectuoso, aunque los adelantos jurisprudenciales continuaron, y en 1997 se expidió la Restatement of torts: product liability que es mucho más precisa en cuanto a la noción de defecto y tipos de defecto, deberes de información, reglas de causalidad, etc. (Woolcott, 2007a, p. 129-132).

En el ámbito comunitario europeo se encuentra un primer antecedente en el Convenio sobre la Ley Aplicable a la Responsabilidad por Productos Defectuosos del 2 de octubre de 1973 y en el Convenio Europeo sobre la Responsabilidad Derivada por Productos Defectuosos de 1977 (Ghestin, 1987, p. 111).

Aparecieron varios proyectos de directivas, uno de 1976 y otro de 1979 , los cuales influyeron significativamente en la adopción de la directiva 374 de 1985, la cual se complementó en 1989 para incluir los productos agrícolas (Munar, 2013, p. 191). Después se expidieron la directiva 95 del 3 de diciembre de 2001 del Parlamento Europeo y del Consejo -relativa a la seguridad general de los productos-y el reglamento 765 de 2008 del Parlamento y del Consejo Europeo, que completan la directiva de 1985 con un sistema de prevención para que los productos que se pongan en el mercado sean seguros.

\section{El principio base: el deber de segu- ridad.}

El régimen de responsabilidad por productos defectuosos surge como consecuencia del deber de seguridad que las normas de protección al consumidor imponen a los productores y proveedores en el mercado, siendo este uno de los pilares en que reposa el derecho del consumo (Villalba, 2012, p. 42). El mandato constitucional se consigna en el artículo 78 de la Constitución Política, que ordena garantizar la calidad de los bienes ofrecidos a los consumidores y consagra la responsabilidad de quienes atenten contra la salud y seguridad de estos. Para materializar tal pretensión, el artículo 3.1.2. de la ley 1480 de 2011 reconoce como derechos de los consumidores que los productos no les causen daño en condiciones normales de uso y a la protección contra las consecuencias nocivas para su salud, su vida o su integridad.

Igualmente, la norma consagra como uno de sus principios base "la protección de los consumidores frente a los riesgos para su salud y seguridad" (art. 1, núm. 1), así como en el artículo 6 reitera el deber de seguridad y enuncia la consecuente responsabilidad administrativa y por producto defectuoso, la cual se trata en los artículos 19 y siguientes del texto legal.

No obstante, se subraya que el deber de seguridad tiene un contenido muy extenso, y en sentido amplio implica la obligación que tiene el productor $\mathrm{y} / \mathrm{o}$ el proveedor de poner solo productos seguros en el mercado y dado el caso, responder por la salud e integridad física del consumidor o de sus bienes.

La obligación de seguridad nace de las exigencias de la vida en sociedad y pesa sobretodo profesional que instala un producto o servicio en el mercado (Calais- Auloy \& Steinmetz, 2006, p. 301). Este concepto adquiere gran holgura, puesto que cobija en algunos eventos, como en la prestación de servicios, que el consumidor no sea lesionado por el uso directo o indirecto 
del bien. Por ejemplo, en el derecho comparado encontramos el caso "Ledesma" en Argentina, en el cual se sancionó al prestador del servicio de transporte masivo por las lesiones que sufrió un consumidor-pasajero al ser arrollado por una multitud que desciende del vagón del tren (María Leonor Ledesma vs. Metrovías S. A., 2008); o el conocido caso "Mosca", también en la Argentina, en que se extendió la responsabilidad para proteger a quien sin haber ingresado a un estadio de fútbol y hallándose en las inmediaciones, resultó dañado por una piedra arrojada desde el interior (Hugo Arnaldo Mosca vs. Provincia de Buenos Aires -Policía Bonaerense- $\mathrm{y}$ otros, 2008).

Así mismo, la obligación de seguridad puede suministrarse cuando un consumidor es agredido o violentado dentro del almacén del productor o proveedor. Incluso en algunos casos citados por la doctrina, sería controvertible la aplicación de la norma de protección al consumidor. Barrientos (2010) cita un caso en el cual, aunque obedece a un fallo aislado de la Corte de Apelaciones de Santiago, se administró el deber de seguridad, pues un consumidor sufrió el robo de su vehículo en el estacionamiento de un supermercado mientras efectuaba algunas compras (p. 42).

Ahora bien, el deber de seguridad en sentido restringido tiene dos manifestaciones claramente identificables, la primera, a través de un régimen administrativo de control de calidad e idoneidad de los productos que circulan en el mercado, que opera de manera preventiva y que tiene a cargo la Superintendencia de Industria y Comercio (SIC) junto con contras entidades como el Instituto Nacional de Vigilancia de Medicamentos y Alimentos (Invima), el Instituto Colombiano Agropecuario (ICA), entre otros. Mediante este sistema, las autoridades velan por ejercer un control que garantice condiciones mínimas de seguridad de los productos que ingresan al mercado y se impida que los consumidores sufran perjuicios por el uso de los bienes y servicios, lo cual se satisface a través de diferentes instrumentos, tales como el cumplimiento de reglamentos técnicos, las normas de etiquetado que imponen deberes de información lato sensu y de advertencia, los registros sanitarios que emite el Invima y por último, el control de productos riesgosos que administrativamente tiene a cargo la SIC, por ejemplo el retiro preventivo de productos que ofrezcan riesgos a los consumidores, recientemente el caso de las máscaras de Spiderman en Colombia mediante resolución 60220 de 2012.

A su vez, este deber preventivo se pone en práctica con el mal llamado deber de información (deber de alerta), que aparece en el artículo 19 de la ley 1480 de 2011 y que contempla la responsabilidad solidaria del miembro de la cadena de producción, comercialización o distribución que tenga conocimiento de un defecto que ha producido o puede producir un evento adverso que atente contra la salud, la vida o la seguridad de las personas, y no tome las medidas correctivas frente a los productos no despachados y los puestos en circulación, o no informe el hecho dentro de los tres días siguientes a la autoridad que determine el Gobierno Nacional.

También existen sistemas de alerta por productos defectuosos como el sistema Rapex en la Unión Europea y el sistema americano de alerta sobre seguridad de productos de la Organización de los Estados Americanos (OEA). La última expresión de este deber está en los recalls o alertas que las empresas de modo preventivo, ya sea por mandato legal o por responsabilidad frente al mercado, efectúan cuando evidencian un problema de seguridad de un bien. Este subsistema es muy importante porque es el que evitará que los consumidores sufran daños en las relaciones de consumo. En el derecho comunitario europeo la directiva 95 de 2001 relativa a la seguridad de los productos regula el asunto. El segundo régimen o subsistema no opera de forma preventiva, sino que lo hace con ocasión de la ocurrencia de un 
daño sufrido por el consumidor, se trata de la responsabilidad por productos defectuosos, tema central del presente artículo.

\section{Ámbito de aplicación.}

La responsabilidad por productos defectuosos tiene vocación de aplicarse cuando a consecuencia de un error de fabricación, diseño o información, el consumidor o usuario de un bien o servicio (producto) sufre un daño en su integridad física o en sus bienes. Conforme a este concepto se necesita que se esté frente a un verdadero daño que reciba el consumidor de un producto; es decir, que el producto haya causado el perjuicio a la integridad física de quien lo esté usando o a los bienes de este, como resultado de un defecto atribuible al productor del bien.

La ley 1480 de 2011 cobija expresamente como daños derivados de esta clase de responsabilidad, "la muerte o lesiones corporales causados por el producto defectuoso y los producidos a una cosa diferente al producto defectuoso" (art. 20, núm. 1-2). De acuerdo con lo anterior, debe aclararse que el evento en que un producto no funciona, o no lo hace en debida forma, pertenece a otro ámbito de las obligaciones del productor, aquel de la garantía de bienes y servicios por la calidad e idoneidad de los mismos, regulado por la misma norma de manera independiente en sus artículos 7 al 17. Así las cosas, un producto puede ser de escasa calidad pero no defectuoso y si el bien no sirve para el fin destinado, el consumidor tendrá que ejercer las acciones derivadas del contrato de consumo (Larrosa, 2011, p. 215), es decir, las relativas a la calidad e idoneidad. Esto no descarta que en algunas circunstancias puedan coincidir las dos obligaciones, como en el suceso en que a raíz de un defecto de fabricación el bien le ocasiona daño al consumidor, verbigracia, una bolsa de aire de un vehículo que no funciona bien y origina lesiones al conductor.

Debe recordarse, que para la ley colombiana de protección al consumidor el concepto de producto es amplio, ya que al no haberse hecho distinción, comprende bienes muebles e inmuebles, corporales e incorporales, y servicios (art. 5, núm. 6) ${ }^{1}$. Este concepto es más estrecho en algunos ordenamientos jurídicos, por ejemplo el Texto Refundido de la Ley General para la Defensa de los Consumidores y Usuarios (TRLGDCU) de España que siguiendo la directiva europea, excluye inmuebles y servicios, al definir al producto como "cualquier bien mueble, aun cuando esté unido o incorporado a otro bien mueble o inmueble, así como el gas y la electricidad" (art. 136).

Como la ley colombiana no hizo exclusiones concretas del marco de cobertura de la responsabilidad por productos defectuosos, quedó allí incluida la responsabilidad por servicios defectuosos, a diferencia de otros ordenamientos jurídicos donde se excluyen expresamente, y este aspecto resulta novedoso aunque de cierta manera controversial. Así los daños derivados de un servicio defectuoso entran en este régimen de responsabilidad objetiva, tales como los servicios públicos domiciliarios (agua potable, gas y electricidad), los servicios de salud (médicos u odontológicos), los servicios de transporte público, entre otros.

\section{La noción de producto defectuoso.}

Hay una diferencia entre el concepto de producto defectuoso y el de producto nocivo, siendo este último el que por su naturaleza puede ocasionarle un daño al consumidor, mas no por conductas atribuibles al productor o proveedor del bien, por ejemplo, el tabaco o las bebidas alcohólicas. Por su parte, producto peligroso es el que puede provocar mayores daños por su naturaleza misma, por ejemplo, un cuchillo $\mathrm{y}$ un pesticida.

Ahora bien, un producto peligroso no es defectuoso si se cumple con la debida información acerca de su correcto uso, de tal forma que ofrece la seguridad que cabe legítimamente esperar (Parra, 1999, pp. 501-502, citado por 
Barrientos, 2010, p. 119), por lo tanto, si es seguro no es defectuoso. Al respecto señalan Ruiz y Marín (2006) que la peligrosidad es una cuestión de facto. Normalmente el control frente a este tipo de productos nocivos o peligrosos en el mercado, consiste en un deber de advertencia obligatorio a cargo de los productores o proveedores del bien sobre su utilización, conservación y riesgos inherentes al consumo.

La ley brasileña hace la distinción entre estos términos y se refiere a los productos potencialmente nocivos o por lo regular peligrosos en el artículo 9 del Código de Defensa do Consumidor (CDC), para los cuales impone un deber de información a cargo del productor, quien de forma ostensiva y adecuada deberá informar sobre la nocividad y peligrosidad del bien. No obstante estar diferenciados los conceptos, un producto peligroso puede ser además defectuoso cuando presenta deficiencias de información sobre el peligro que conlleva su manipulación o no incorpora las indicaciones precisas sobre su utilización y a consecuencia de ello, le genera un daño al consumidor (Gutiérrez, 2011, p. 676). En todo caso, ya sea que se trate de productos nocivos, peligrosos, o incluso en la generalidad de los productos, cuando los riesgos sean previsibles, la obligación del productor será informar y advertir al consumidor sobre el riesgo y el debido empleo del bien, porque no advertirlo torna el producto además en defectuoso.

Para Ruiz y Marín (2006) el concepto de producto defectuoso y/inseguro es normativo, lo que no sucede para la noción de producto peligroso (p. 5). La ley 1480 de 2011 define al producto defectuoso como: "aquel bien mueble o inmueble que en razón de un error [en] el diseño, fabricación, construcción, embalaje o información, no ofrezca la razonable seguridad a la que toda persona tiene derecho" (art. 5, núm. 17). Por ende, un producto defectuoso es aquel que a consecuencia de un defecto atribuible al productor causa daño al consumidor del bien o servicio.

Para la normativa española se entenderá por producto defectuoso aquel que no ofrezca la seguridad que cabría legítimamente esperar, teniendo en cuenta todas las circunstancias y, en especial, su presentación, el uso razonablemente previsible del mismo y el momento de su puesta en circulación (TRLGDCU, art. 137). El concepto de defecto se circunscribe para la doctrina a la falta de seguridad del producto y no a su ausencia de aptitud para el uso (Paniagua, 2012, p. 320), ni en la conformidad con el contrato (Calais-Auloy, 2006, p. 347). La doctrina española insiste además en que el cumplimiento de normas vigentes o que se cuente con autorización administrativa para su fabricación, no exonera de responsabilidad al fabricante, porque la regulación española habla de la seguridad que cabría esperar "legítimamente" y no dice "legalmente", por lo cual se puede probar la falta de seguridad del mismo y la consiguiente responsabilidad del productor (Gutiérrez, 2011, p. 667; Herrera, 2007, p. 171).

Al respecto surge una crítica al concepto colombiano, porque se centra en la idea de error y no en la de defecto, que se ata a la noción de seguridad en la mayoría de ordenamientos jurídicos. En efecto, si el error es un "concepto equivocado o juicio falso" o una "acción desacertada o equivocada", según el Diccionario de la Real Academia Española, hacer girar la definición de producto defectuoso en torno al significado de error, implica dotarla de una subjetividad que no merece, y acercarla a la idea de falla humana, con tintes de responsabilidad por culpa, lo cual resulta inadmisible.

Nótese que las acepciones para producto defectuoso en el derecho comparado se centran en el concepto de seguridad legítimamente esperada o razonable. La normativa comunitaria europea (directiva 374 de 1985, art. 6), la ley brasileña (ley federal 8078 de 1990, art. 11, núm. 1) y el Código de Protección y Defensa del Consumidor de Perú (ley 29571 de 2010, art. 102) acogen esta tendencia en las disposiciones nacionales que regulan el asunto. Así, el criterio que predomina en esos preceptos es el objetivo, con enfoque en las expectativas del consumidor 
(las generales y no las particulares) -víctima, porque sus expectativas particulares pueden variar según sus consideraciones subjetivas(Paniagua, 2012).

No obstante este juicio, tampoco es completo, las "expectativas legítimas" no permiten al juez tener las herramientas necesarias para determinar la defectuosidad de un producto, de tal forma que aplicar un test de "expectativas legítimas" sin información adicional, no facilita saber si un medicamento es defectuoso porque tiene efectos secundarios o si un vehículo lo es porque no tiene bolsas de aire o frenos ABS (Taylor, 1999, p. 55). Señala Gutiérrez (2011) que en el ámbito español la falta de seguridad es el sustrato del carácter defectuoso de un producto (p. 663), siendo esta la tendencia, como ya lo dijimos.

Sin embargo, la Corte Constitucional y la Corte Suprema de Justicia colombianas en sendas sentencias, anteriores a la ley 1480 de 2011, acogieron la teoría europea al admitir que para comprobar el defecto, el consumidor debe probar solamente que el producto no brindaba la seguridad a que una persona tiene legítimamente derecho (sentencia C-1141 de 2000 y sentencia del 30 de abril de 2009, Exp. 25899 3193992199900629 01). Se evidencia entonces una disyuntiva entre los alcances de la noción de producto defectuoso planteada por las altas cortes y la que toma la ley 1480 de 2011, la cual probatoriamente puede tener consecuencias indeseables en perjuicio del consumidor si se emplea de manera errada, por lo que se reitera el reproche endilgado.

En nuestro sentir, para corregir esta falencia, la jurisprudencia tendrá un papel muy importante clarificando el radio de este tipo de responsabilidad y sobre todo, reafirmando la doctrina que sobre el tema las altas cortes habían alcanzado a definir hasta el momento de entrada en vigencia del nuevo texto, para hacer una correcta interpretación del estatuto de protección al consumidor ceñida al principio pro consumatore. Además, la ley 1480 de 2011 crea una ruptura conceptual porque entiende la seguridad como:

Condición del producto conforme con la cual en situaciones normales de utilización, teniendo en cuenta la duración, la información suministrada en los términos de la presente ley y si procede, la puesta en servicio, instalación y mantenimiento, no presenta riesgos irrazonables para la salud o integridad de los consumidores. En caso de que el producto no cumpla con requisitos de seguridad establecidos en reglamentos técnicos o medidas sanitarias, se presumirá inseguro (art. 5, núm. 14).

Esta apreciación se cimienta en el carácter de lo "razonable" y de ella se puede inferir que un producto inseguro será aquel que presenta riesgos irrazonables para la salud o integridad de los consumidores de acuerdo con las condiciones normales de utilización, duración y la información suministrada. Podemos concluir entonces que producto inseguro y producto defectuoso pretendieron ser lo mismo para efectos de esta ley, pero infortunadamente ambas definiciones no coinciden. La explicación de seguridad no incluye en ninguna parte el concepto "error". De igual modo, la presunción de inseguridad creada en esa tesis, implicará que cuando el producto no cumpla con el reglamento técnico o con las medidas sanitarias establecidas, el consumidor no tendrá que probar el defecto o carácter defectuoso del bien, tan solo pesará sobre él la prueba de la existencia del reglamento o medida sanitaria y del nexo causal, acentuándose la objetividad del régimen.

La normativa comunitaria europea da unas pautas adicionales para ponderar el carácter defectuoso de un producto, tales son: a) la presentación: este aspecto evoca la seguridad que pueda esperarse del bien en función de su aspecto externo, envase, embalaje y etiquetado (Gutiérrez, 2011). Un producto puede ser inseguro por su presentación cuando la forma del envase induce a error al consumidor, por ejem- 
plo, una botella de pesticida que tenga la forma habitual de una botella de una bebida; y b) el uso razonablemente previsible: no el que previó el productor sino el que puede prever el consumidor. Estos usos pueden ser no habituales, inadecuados o abusivos (usos impropios previsibles).

Lo que se descarta del todo son los usos irrazonables que no son objetivamente previsibles, como el mítico pero nunca comprobado caso en el derecho anglosajón, de la mujer que secaba su mascota en el horno microondas. En cambio, Solé Feliu (1997, citado por Gutiérrez, 2011) cita como ejemplo de uso inapropiado en absoluto previsible, la caída de un ascensor por exceso de ocupantes. O el que los niños se lleven los juguetes a la boca, o el que un adulto haga lo mismo con la varilla de las gafas o el bolígrafo, por lo cual cabe exigir que en la fabricación de estos se utilicen materiales y pinturas no tóxicos (Martín \& Solé, 2005. p. 169). Se agrega que el carácter de razonabilidad debe valorarse según el consumidor, por ejemplo si es un infante quien usa el producto (Gutiérrez, 2011).

Otra pauta que brinda la normativa comunitaria europea para conocer si un producto es defectuoso, es el momento de puesta en circulación de este: dicho momento se torna relevante como quiera que a partir de él se presumirá la responsabilidad del productor, ya que se considera causal de exoneración el no tener el producto en circulación y el hecho de que el defecto no existiera cuando se puso el producto en el mercado o que apareciera más tarde (directiva 374 de 1985, art. 7). Al respecto indica la doctrina que la directiva no explicitó cuál es el momento de la puesta en circulación, como sí intentan hacerlo algunas normas nacionales, siendo la más concreta la contenida en el Código del Consumidor italiano, según el cual, hay puesta en circulación del producto cuando se entrega al adquirente, al usuario o a un auxiliar de estos, también en exhibición o en prueba, o cuando se entrega al transportista o agente de transportes para el envío al adquirente o usuario (Gutiérrez, 2011, p. 689).

Estos conceptos auxiliares no se recogieron en la ley 1480 de 2011, aunque no se puede decir que estén totalmente ausentes de la misma, pues en lo referente a la puesta en circulación, el artículo 22 se valió de ellos al consagrarlos como un eximente de responsabilidad, de tal forma que en Colombia no existe un criterio delimitado ni se ha debatido aún sobre qué es el momento de puesta en circulación. En cuanto a los usos previsibles, llama la atención que en el artículo 3 se declara el derecho a la seguridad de los consumidores y se dice que estos tienen derecho "a que los productos no causen daño en condiciones normales de uso", haciendo alusión de manera implícita a que el deber de seguridad y la responsabilidad derivada de este, se ciñen a eventos de usos normales de los productos. Posteriormente ratifica este criterio cuando en el artículo 5 en la definición de "seguridad", emplea la expresión "situaciones normales de utilización", por lo que se puede inferir que un criterio adoptado para determinar la defectuosidad de un producto es el de el "uso normal", el cual, es evidente, no es un juicio cerrado, porque precisar qué es un uso normal implica para el juzgador un análisis de contexto y ponderar además qué tipo de usos son anormales, frente a lo cual tendrá que valorar las condiciones del consumidor, la información dada, la publicidad utilizada, la apariencia del producto, entre otros factores. Así mismo, al disponer en el artículo 22 como causal de exoneración la culpa exclusiva del afectado, la discusión acerca del uso "anormal" del producto por parte del consumidor, estará de seguro a la orden del día para romper el nexo causal por parte del productor.

Debe agregarse que esa misma explicación estima los "riesgos irrazonables", porque según ella, un producto es defectuoso solo si presenta ese tipo de riesgos para el consumidor. Lo anterior permite entonces deducir que hay riesgos razonables en condiciones normales de 
utilización de un producto, como por ejemplo chocar un vehículo o contraer un cáncer por fumar tabaco. Parece que el legislador quiso ratificar que el uso de productos presenta riesgos, muchos de ellos razonables, y que frente a estos no cabe responsabilidad del productor si este informó debidamente al consumidor sobre los mismos.

\section{Clases de defectos.}

La ley 1480 de 2011 señala qué clases de "errores" (en realidad debería decir defectos) dan lugar a valorar un producto como defectuoso (art. 5, núm. 17), en primer lugar defectos de diseño, es decir, aquellos referentes a la concepción del bien, su estructura o inclusive su estética. En el defecto de diseño todos los productos de la serie o modelo, sin excepción alguna, han sido mal ideados o proyectados de tal suerte que resultan peligrosos (Coderch et al., 2003, p. 15). Para Coderch et al. (2003) hay dos criterios para determinar si existe un defecto de diseño, primero el test de las "expectativas razonables del consumidor" -acogido en el derecho comunitario europeo y la ley española-, según el cual un producto está defectuosamente diseñado cuando defrauda las expectativas razonables del consumidor y lo lleva a error causándole daño. Segundo, el riesgo-utilidad -aceptado en las cortes estadounidenses-, que estima un diseño defectuoso cuando los riesgos previsibles de daño que presenta el bien, podrían haber sido reducidos con la adopción de un diseño alternativo, razonablemente viable y más seguro (p. 15, este tema lo explica ampliamente Owen, Madden, \& Davis, 2000 pp. 443-500).

En armonía con Borghetti (2004) esta teoría del riesgo-utilidad, influenciada por la escuela del análisis económico del derecho, la recogieron los jueces norteamericanos, para los cuales se asumió que "un comportamiento es irrazonable y por lo tanto culpable cuando el costo de los daños que pudiese provocar, ponderado por la probabilidad de su ocurrencia, es superior al costo de las precauciones que hubieran podido evitar su ocurrencia" (p. 54). Estos dos criterios obedecen a desarrollos doctrinales y judiciales, y la ley colombiana no se refiere a ellos, por lo tanto, queda en expectativa el dictamen que se adopte.

En segundo lugar, de las clases de defectos, se encuentran los errores de fabricación: los que pueden surgir en un problema de producción, tales como aquellos debidos al mal funcionamiento de una máquina o un yerro humano y que generan un defecto en una serie de producción. La doctrina insiste en que estos defectos pueden afectar algunos ejemplares de una serie, siendo el resto de la producción correcta (Gutiérrez, 2011, p. 678). En tercer lugar problemas de construcción para el caso de inmuebles, en los cuales un vicio de construcción da lugar a este tipo de responsabilidad. En cuarto lugar problemas de embalaje o empaquetamiento que afecten la debida preservación del bien o alteren sus características de modo que se vuelva inseguro; y en quinto lugar problemas de información, evento en el cual los riesgos previsibles de daño que presenta el producto pueden reducirse o evitarse mediante informaciones o advertencias razonables y su omisión convierte el producto en inseguro (Coderch et al., 2002, p. 17).

En este último caso el producto no tiene un defecto, pero a causa de una indebida información al consumidor acerca del modo de utilización, contraindicaciones o advertencias, el consumidor sufre perjuicios en su integridad o en sus bienes. Es más, en casos especiales el defecto puede recaer en circunstancias particulares del consumidor (warning defects), hipótesis en la que el bien no tiene un defecto pero puede ser inseguro para ciertas personas, verbigracia, un alimento o medicamento que puede motivar una reacción alérgica a algunos sujetos. Este problema se corrige preventivamente a través de un deber de advertencia calificado que pesa a cargo del productor (Woolcott 2007b p. 121). 


\section{Características y configuración de la responsabilidad por producto defectuoso.}

\section{Características.}

El estudio de este tipo de responsabilidad evidencia tres características que a continuación se tratarán.

\section{De la responsabilidad civil a la responsabi- lidad de mercado.}

Engeneralseconsideraalaresponsabilidad del productor por los daños ocasionados por productos defectuosos, una subespecie de la responsabilidad civil, no obstante este tema en Colombia sufrió una precisión conceptual por parte de la Corte Constitucional, la cual en sentencia C-1141 de 2000 expresó:

La responsabilidad del productor y del distribuidor surge ex constitutione y puede por ello ser deducida por el consumidor del producto o el usuario, con independencia de que exista o no un vínculo contractual directo con los primeros. En este sentido, las garantías atingentes a la calidad o idoneidad de los bienes y los servicios, no se ofrecen exclusivamente al primer adquirente; ellas se disponen frente a la categoría de los consumidores y usuarios. $E l$ productor profesional produce para el mercado, se beneficia del mercado y debe responder ante el mercado. En este caso, el mercado está constituido por los consumidores y usuarios. La responsabilidad de mercado -secundada por la Constitución y la ley-, no contractual, acredita la reivindicación igualitaria que ha querido la Constitución introducir bajo el concepto de consumidor o usuario (énfasis fuera de texto).

Se observa entonces que se trata de una especie de responsabilidad especial, que se aleja de los parámetros de la responsabilidad civil tradicional, porque en ella pierde toda relevancia discriminar si el origen del vínculo obligacional es de carácter contractual o extracontractual, es por ello una responsabilidad especial de orden legal definida como "responsabilidad de mercado". El profesor Hinestrosa (2003) bien señaló que el tratamiento igual de las víctimas en el derecho del consumo, es un aspecto positivo que aproxima a una unificación de los regímenes tradicionales de la responsabilidad civil (p. 331). En el mismo sentido, Farina (2009) sostiene que la antigua distinción entre responsabilidad contractual y extracontractual no debe aplicarse para resolver cuestiones derivadas de la relación de consumo (p. 468).

Woolcott (2007b) asevera en su obra que en el derecho norteamericano se tuvieron en cuenta varios factores para valorar la responsabilidad del productor como una especie de responsabilidad especial, entre ellos, la información imperfecta que recibe el consumidor por su falta de conocimiento experto; la disparidad del poder contractual en el mercado, derivada de la mayor capacidad de negociación del productor a través de las formas de contratación estándar que revaluaron el papel del contrato como mecanismo de protección a la víctima; y el tema de la distribución de los riesgos, porque el productor está en mejor capacidad de asumir los riesgos (costos) que dimanan de los defectos de sus productos, mientras que la víctima (consumidor) no está en grado de protegerse a sí mismo y contraer los costos.

Para Costa (1998) dos fundamentos dan lugar a la consideración de la responsabilidad del productor: la expectativa del consumidor que adquiere un producto creyendo que responderá a sus motivaciones; y la seguridad en el uso del producto (p. 4). En nuestras palabras, esto se traduciría en la confianza que tienen los consumidores en que los productos que adquieren son seguros, ya sea porque tienen la convicción de que existen controles estatales al respecto o porque presumen de la buena fe del productor; y en la obligación legal de seguridad que pesa sobre los productores. Según Weingarten (2007) el bien jurídico 
tutelado es la confianza que el consumidor deposita en que se le brindará un bien o servicio eficiente, confiable, seguro y, de acuerdo con la expectativa que objetivamente genera, nacen obligaciones específicas, si esas expectativas se ven frustradas y causan daño emana la responsabilidad del productor (p. 237).

\section{Es responsabilidad objetiva (sin culpa).}

El régimen tradicional de responsabilidad civil con base en el concepto de culpa, se mostró insuficiente para cumplir con la función resarcitoria en los casos de daños derivados del proceso de industrialización (Cillero, 2000, p. 90), y planteó la necesidad de una reformulación de la regla de responsabilidad para ciertos casos, primero utilizando la teoría de los riesgos que influenció el surgimiento de la responsabilidad objetiva, para luego responder a otros desafíos como el de proteger a la parte débil, sobre la cual pesaba una carga probatoria muy alta al tener que demostrar la culpa, sobre todo por la hiposuficiencia que caracteriza al consumidor, quien por carecer de conocimientos técnicos pocas veces podría acreditar la culpa del productor.

En consecuencia, la regla tradicional se alteró y la premisa es la siguiente: el productor crea unos riesgos con la puesta de bienes en el mercado y es él quien se lucra y obtiene ventajas económicas de esa actividad, tal y como lo sugirió la Corte Constitucional en la referida sentencia de 2001. El riesgo creado es el factor de atribución de responsabilidad (Mosset \& Wajntraub, 2008, p. 244), por ende, el nivel de diligencia que se le exige es superior y la responsabilidad se agrava para pasar a un sistema de inversión de la carga de la prueba con culpa presunta, aquí el productor solamente podrá romper el nexo causal alegando causa extraña.

El sistema de la responsabilidad objetiva se muestra entonces como una solución frente al problema de la responsabilidad del productor, al repartir de forma equitativa los riesgos inherentes a la producción de la técnica moder- na (directiva 374 de 1985). El brillante argumento del juez Traynor en el caso Escola vs. Coca Cola Bottling Co. Of Fresno, sostuvo que el verdadero estándar de responsabilidad por productos debe ser objetivo, ya que los fines del derecho de daños son principalmente económicos: la disuasión y el seguro; por ello, las reglas de la responsabilidad deben diseñarse para minimizar el riesgo y dispersarlo tanto como sea posible entre las personas y el tiempo, y dada la posición que ocupan consumidor y productor en el mercado, quien está en mejor postura para asumir esos costos es el productor, ya sea invirtiendo en medidas de precaución o determinando qué riesgos vale la pena asumir (Coleman, 2010, p. 410). El profesor Stiglitz (2009) explica muy bien los alcances de considerar esta especie de responsabilidad como objetiva:

Por tratarse de un régimen de responsabilidad objetiva (art. 1113 CC.), el productor no puede liberarse demostrando simplemente que no actuó con culpa. Únicamente se exime de responsabilidad en los casos de ausencia de relación de causalidad: por caso fortuito o fuerza mayor, o por culpa de la víctima, o por el hecho de un tercero extraño (p. 409).

Es decir, la responsabilidad del productor se configura prescindiendo de su culpa o negligencia, pues no puede alegar prudencia y diligencia para romper el nexo causal. En la ley 1480 de 2011 esas causales de exoneración se contemplan taxativamente y se explicarán en líneas posteriores. Empero, el carácter objetivo de la responsabilidad del productor por productos defectuosos queda en entredicho, aun su constitucionalidad para algunos, por la existencia de causales de exoneración y la inclusión del concepto "error" en la explicación de producto defectuoso (Giraldo, Caycedo, \& Madriñan, 2012, p. 22).

\section{Es responsabilidad solidaria.}

La ley 1480 de 2011 establece la responsabilidad solidaria entre el productor y el proveedor por los daños ocasionados por un 
producto defectuoso. Esta solidaridad implica la superación total de la disyuntiva entre la responsabilidad contractual o extracontractual, para dar paso a un régimen tuitivo que involucra en principio a todos los miembros de la cadena de valor, con prescindencia de los alcances del clásico principio civilista de la relatividad de los actos jurídicos res inter alios acta. Según Tamayo Jaramillo (2007) se supera el efecto relativo de los contratos para consolidar

[...] una responsabilidad solidaria de todas las personas que participen en la cadena de producción y distribución del producto dañino, frente al tercero, consumidor o no, que finalmente sufra el daño como consecuencia del defecto o falta de calidad del producto. En esta forma, el fantasma de la diferencia entre responsabilidad contractual y extracontractual tiende a reducirse o a eliminarse en este tipo de daños (p. 117).

Los sujetos responsables solidariamente son, al tenor de la ley colombiana (ley 1480 de 2011, art. 20), el productor y el expendedor (o proveedor), esto es, según las definiciones incorporadas en la norma, todos los miembros de la cadena de valor, incluyendo a aquel que coloque su nombre, marca o cualquier signo distintivo en el producto (fabricante aparente). La directiva 374 de 1985 es precisa en tratar como responsable al fabricante de la materia prima o de una parte integrante del bien. A pesar de que en la ley colombiana no quedó clarificada la responsabilidad de este último productor, nuestra posición es que debe tomarse como solidariamente responsable y puede ser llamado en garantía por el productor o proveedor, o en el caso de que sean condenados a reparar el daño, podrán repetir contra este. La misma directiva consagra la responsabilidad directa del productor pero la responsabilidad del proveedor (suministrador) tiene naturaleza subsidiara en el derecho comunitario europeo, en este aspecto se muestra más generosa la norma colombiana. Parra (2002) explica este régimen diferencial en la regulación europea así:
Esta opción obedece a dos tipos de consideraciones: en primer lugar el hecho de que generalmente es el productor el causante de los defectos de los productos y quien, por tanto, está en mejores condiciones de prevenirlos y evitarlos; pero también, y en segundo lugar, porque se considera preferible que no se multipliquen los seguros de responsabilidad entre los distintos miembros de la cadena de elaboración y distribución de los productos cuando, en definitiva, es el fabricante quien está en mejores condiciones de absorber el daño a través de los precios y de su repercusión en el seguro que concierte (p. 371).

Es importante destacar además que en la ley colombiana dentro de la noción de "proveedor" quedaron contenidas aquellas personas que ofrezcan, suministren, distribuyan o comercialicen bienes sin ánimo de lucro.

\section{Requisitos.}

De acuerdo con lo expuesto y lo estipulado en la ley 1480 de 2011 (art. 21) el consumidor tendrá que probar el daño, el defecto y el nexo causal. En cuanto a la prueba del daño, esta se impone como un presupuesto esencial de la responsabilidad, indiscutible por demás, de tal forma que el consumidor debe probar que sufrió un daño en su integridad física o en aquellos que lo rodean, o que sus bienes hayan sufrido daños, exceptuando al mismo producto defectuoso.

En lo atinente al defecto del bien, el consumidor debe probar que este no cumplía con la seguridad razonablemente esperada, que el producto no operó en las condiciones que debía funcionar o que no satisfacía las medidas de seguridad normales o las indicadas por el productor. En modo alguno la prueba del defecto conduce a que se demuestre técnicamente el error en que incurrió el productor, porque ello impondría al consumidor una carga probatoria tan grande que haría nugatorio todo este régimen de responsabilidad objetiva. Munar (2013) comparte esta apreciación al sostener 
que la demostración del carácter defectuoso del producto implica la carga clásica de la prueba, por cuanto deposita en los hombros de la víctima acreditar la prueba fáctica causante de la responsabilidad imputada (en el mismo sentido Pipaon, 2010, p. 218). Sin embargo, este autor cree que no incumbe a la víctima especificar ni probar las omisiones o fallas en que hubiese incurrido el fabricante en el proceso de manufacturación, posición que compartimos en la medida que comprometería finalmente la demostración de la culpa del demandado (Munar, 2013).

En igual sentido se expresa Hinestrosa (2003), quien afirma que evidenciar que el producto tenía defectos y que estos fueron anteriores a su lanzamiento es algo que debe darse por supuesto, y debe desvirtuar el productor, quien por su misma posición está en mejores condiciones de comprobar la entrega inicial del producto en perfectas condiciones, o sin el defecto que se le atribuye (p. 345). La directiva europea establece una presunción de anterioridad del defecto, lo que facilita la tarea probatoria de la víctima (Calais-Auloy \& Steinmetz, 2006, p. 348).

En estricto sentido el consumidor debe probar tan solo la existencia del defecto pero no sus causas, aunque de manera equívoca la ley 1480 de 2011 haya incluido la palabra "error" en la definición de producto defectuoso. Empero, la figura de la carga dinámica de la prueba sin duda permitirá al juez radicar en cabeza del productor la prueba de la anterioridad del defecto, y en algunos casos de complejidad científica, trasladarle por completo la prueba del defecto, por ser quien técnicamente tiene la mejor posición para probarlo.

Por último, el nexo causal, la ley le impone al consumidor que pruebe la relación de causalidad entre el defecto y el daño sufrido. No obstante, tal y como lo señala Monroy (2010), no es suficiente fijar el nexo causal entre un producto y el daño, sino que es necesario que el daño sea imputable a un defecto del producto (p. 12). La prueba de este nexo causal se torna relativamente fácil cuando son daños ocurridos en masa o en series numerosas de un producto, mientras que en aquellas situaciones en que solo un número limitado de productos padece el defecto, la carga de la prueba para el consumidor es alta. Esto se hace manifiesto en los dos casos de responsabilidad del productor sobre los cuales la Corte Suprema de Justicia ha tenido la posibilidad de pronunciarse en casación; allí las pretensiones del consumidor no procedían por la ausencia de prueba del nexo causal (sentencias de 30 de abril y 24 de septiembre de 2009). En sentencia del 24 de septiembre de 2009 la Corte dijo lo siguiente sobre el nexo causal en un asunto de responsabilidad por producto defectuoso:

Puntualmente por ello es que la Corporación, en la citada sentencia de 30 de abril de 2009, al poner en la mira "la distribución de la carga probatoria en la responsabilidad de esta especie", enfatizó que como a la víctima le toca "probar el perjuicio que padeció, el carácter defectuoso del producto y la relación de causalidad entre este y aquel" [es claro, que el damnificado] "se quedaría en la mitad del camino si se circunscribiera a demostrar únicamente que el producto es defectuoso", [por supuesto] "que su compromiso es de mayor hondura", [en cuanto] "le incumbe probar... [igualmente, que] el perjuicio que padeció fue causado por las condiciones de inseguridad del mismo", [en consecuencia] "[...] corresponde al actor acreditar, también, que la falta de seguridad del producto le causó la lesión que lo afectó, así como las consecuencias que de ella se desprende". [Y si bien] "en algunas ocasiones no será menester acudir a específicos medios probatorios, en no pocos casos, por el contrario, será necesario recurrir a exigentes experticias que pongan de presente la causalidad existente entre el bien fabricado defectuosamente y el detrimento alegado, esto, precisamente, porque la fijación de la relación causal suele concernir con complejas cuestiones científicas que requieren conocimientos especializados", [tanto más cuando se trata de establecer la extensión del resarcimiento] (pp. 38-39). 
Adicionalmente en dicha sentencia de 24 de septiembre de 2009 la Corte enunció:

Por supuesto que la exigencia impuesta al actor de acreditar así mismo el elemento últimamente mentado, no implica que con ello, per se, se ignoren las condiciones de inferioridad en la que suele hallarse el consumidor en su relación con el empresario fabricante del producto o prestador del servicio de que se trate, cual podría ocurrir de llegar a imponérsele la carga de probar, a más de los que vienen referidos, otros presupuestos, pues, como lo expresa la jurisprudencia constitucional, dado que "la posición del consumidor no le permite conocer en detalle el proceso de producción", con mayor razón "si este se desarrolla en condiciones técnicas que solamente son del dominio del empresario", se desconocerían "las circunstancias de inferioridad del consumidor" en los supuestos en que se exigiese "a la persona perjudicada con un producto defectuoso, puesto en circulación por un empresario profesional, cargas adicionales a la prueba del daño, del defecto y del nexo causal entre este último y el primero" (p. 41).

Nótese que la Corte, a pesar de reconocer la inferior capacidad probatoria del consumidor, estima que mínimamente debe probar el nexo causal, sin atenuación alguna.

Sobre la dificultad de la prueba de este nexo causal, Namen (2007) apunta que el juez debe recurrir a indicios y otros medios probatorios que le brinden la convicción de que el demandado le causó el daño al demandante (p. 23). Declara la autora que en todo caso la víctima de un producto, solo deberá probar, el daño y el nexo de causalidad, sin entrar a comprobar si el productor o cualquier otro sujeto interviniente en la producción o comercialización del bien o servicio, actuó de forma negligente o descuidada.

El problema de la demostración del vínculo de causalidad se agrava en circunstancias en que el daño se produce mucho tiempo después del uso del producto, un caso paradigmático fue el del medicamento dietilestilbestrol en los Estados Unidos, el cual entre los años 1947 y 1971 se había prescrito a gran número de pacientes para evitar abortos espontáneos, pero pasado un largo lapso después de la ingesta del fármaco por parte de las madres, las hijas de estas desarrollaron cáncer en el cuello cervical; la dificultad se tornaba evidente, luego de un cuarto de siglo imputar la responsabilidad a un productor particular era de difícil probanza. Los jueces norteamericanos solucionaron este asunto aplicando por primera vez el criterio de la cuota de mercado (market share), según el cual los demandados no serían condenados solidariamente por el total del resarcimiento, sino en proporción a la respectiva cuota del mercado sobre el producto (Woolcot, 2009, p. 121).

Lo dicho evidencia que en algunos casos razonablemente ponderados, los jueces podrían aplicar la carga dinámica de la prueba del nexo causal a favor de la víctima, trasladando esta prueba al productor. Ahora bien, la ley 1480 de 2011 impone la carga de la prueba del nexo causal a la víctima y surge entonces el cuestionamiento sobre la posibilidad de aplicación de la carga dinámica de la prueba admitida en el Código General del Proceso, en este caso de la prueba del nexo causal, en cabeza del productor frente al mandato expreso de la Ley de Protección al Consumidor. Tal y como lo decreta el artículo 167 del Código General del Proceso (CGP) creemos que es posible desplazar la carga de la prueba del nexo causal al productor, con la exigencia de que se suministre verdaderamente en circunstancias de dificultad probatoria para el consumidor. Un grato servicio le prestó la reforma procesal a los consumidores colombianos en este sentido.

\section{Causales de exoneración.}

La ley 1480 de 2011 siguiendo la pauta impuesta en el derecho comparado, consagró unas causales taxativas de exoneración de la responsabilidad en materia de productos defec- 
tuosos, siendo esta la única forma de romper el nexo causal en este ámbito de responsabilidad objetiva. Debe recordarse que el decreto 3466 de 1982, norma que no reglamentó la responsabilidad por productos defectuosos en concreto sino que se refirió a la responsabilidad del productor de manera amplia, también contemplaba en el artículo 26 como causales de exoneración la fuerza mayor, el caso fortuito no sobrevenido por su culpa, el uso indebido del bien o servicio por parte del afectado, o el hecho de un tercero. Esta regla fue objeto de demanda de inconstitucionalidad y en sentencia C-973 de 2002 la Corte Constitucional se pronunció sobre la exequibilidad de las causales de exoneración planteadas por la disposición así:

Al respecto la Corte recuerda que contrariamente a lo que el actor aduce, la norma acusada, así como el conjunto de disposiciones que regulan la responsabilidad de los productores por la idoneidad y calidad de sus bienes y servicios lo que hacen es asegurar el equilibrio entre productores y consumidores que se encuentran, por las características mismas del proceso productivo, en una relación efectivamente desigual, pero en la que la parte más débil no es el productor sino el consumidor.

En este sentido cabe reiterar que el régimen de responsabilidad del productor que se establece en el artículo referido, con la excepción a que se hará referencia más adelante, corresponde al esquema ideado por el constituyente para responder a la asimetría del mercado en el que el consumidor o usuario se encuentra en situación de desventaja.

Es más, en la mentada sentencia además de reiterar la procedencia de esas causales de exoneración, la Corte Constitucional declaró la inexequibilidad del hecho de un tercero "ligado o no al productor mediante relación de trabajo o contractual de cualquier clase" como causal exonerativa de responsabilidad. De la lectura de esta sentencia se puede evidenciar también cómo el precepto anterior no distinguía en realidad entre la responsabilidad por producto defectuoso y la responsabilidad derivada por la garantía de bienes y servicios, y de hecho en el artículo 26 de la antigua norma, se hacía alusión a la responsabilidad "administrativa" por condiciones de calidad e idoneidad contemplada en los artículos 24 y 25 de la misma, pero no había referencia alguna a la responsabilidad del productor por productos defectuosos (omisión al deber de seguridad). Lo que pasa es que la Corte Constitucional en las consideraciones de la sentencia hizo extensiva esta responsabilidad de modo genérico a las infracciones al deber de seguridad, como también lo hizo la Corte Suprema en la sentencia del 30 de abril de 2009.

De esta forma encontramos que el decreto en comento no reglamentó el tema de la responsabilidad por productos defectuosos, pero las altas cortes hicieron extensivas sus normas al tema. Las causales de exoneración que puede alegar el productor consagradas en la ley 1480 de 2011 son:

1. Por fuerza mayor o caso fortuito; es claro que se trata de fuerza mayor o caso fortuito ocurridos después de la puesta en circulación del bien, por lo tanto, los eventos de esta índole que acaecieron con precedencia no son admisibles como exonerativos de responsabilidad. Tamayo (1998) advierte que la existencia de una fuerza mayor no exime de responsabilidad desde que el defecto haya tenido alguna incidencia causal en la producción del daño, por ejemplo, si por un derrumbe sobre una vía una piedra rompe el vidrio delantero de un automotor y las astillas de este por un defecto de fabricación causan daño a un pasajero, el fabricante no podrá alegar que no cometió culpa alguna a raíz de una fuerza mayor (p. 54). Obsérvese que la directiva europea 374 de 1985, no contempla la fuerza mayor ni el caso fortuito como causales de exoneración, y dada la amplitud de la ley colombiana, este criterio deberá ser delimitado por la jurisprudencia.

2. Cuando los daños ocurran por culpa exclusiva del afectado; se trata aquí de mal uso por parte del afectado que puede ocurrir por 
imprudencia o negligencia, como por ejemplo utilizar el bien impropiamente o darle un empleo irrazonable no previsible. Igual sucederá cuando ha sido informado adecuadamente y el consumidor no atiende la información o las advertencias.

3. Por hecho de un tercero; en este caso un tercero ajeno al productor o expendedor manipula o altera las condiciones del producto después de que este ha sido puesto en circulación, por ejemplo modifica el etiquetado, varía el contenido, etc. En materia de responsabilidad del productor, se debe entender por tercero aquella persona que participó en la causación del daño y que no dependa del productor o importador, ni tampoco de los que estos fueren responsables (Vela, 2004, p. 133). Se acota además que el tercero debe ser alguien ajeno a la cadena de comercialización (Hernández \& Frustragli, 2010, p. 10) y que el productor y proveedor únicamente quedarán exonerados de responsabilidad cuando el daño se produce por la actividad exclusiva del tercero, es decir, que si la actividad del tercero contribuye a la producción del daño, pero no es la causa exclusiva porque el defecto del producto existe, el productor y proveedor no se exonerarán de responsabilidad (Díez-Picazo, 1999, p. 155).

4. Cuando no haya puesto el producto en circulación; evento en el cual el producto es puesto en circulación o llega a las manos del consumidor por acción de un tercero diferente al productor, quien no ha lanzado el producto al mercado.

5. Cuando el defecto es consecuencia directa de la elaboración, rotulación o empaquetamiento del producto conforme a normas imperativas existentes, sin que el defecto pudiera ser evitado por el productor sin violar dicha norma; en este caso, por tratarse del cumplimiento de normas imperativas, se exoneran de responsabilidad a los miembros de la cadena de valor, pero esto no es óbice para que el consumidor no pueda hacer recaer la responsabilidad en el
Estado, quien debe actuar a través de entidades que velan por la seguridad de los consumidores como las superintendencias o el Invima, y por ser este además quien tiene la obligación de velar por la seguridad de los consumidores según el artículo 78 de la Constitución Política.

Manifiesta Lasarte (2010) sobre esta causal de exoneración, que las normas no deben dejar opción alguna al productor y además debe existir una conexión directa entre las regulaciones imperativas y el defecto, hasta el punto de que aquellas sean la causa directa de este (p. 294). Dice Reyes (2009) por su parte, que el importador podrá valerse de esta causal basándose en disposiciones imperativas propias del país donde se ha fabricado el producto o del país al que se ha exportado (p. 332).

6. Cuando en el momento en que el producto fue puesto en circulación, el estado de los conocimientos científicos y técnicos no permitía descubrir la existencia del defecto. Esta causal de exoneración conocida como "el riesgo de desarrollo" ha sido polémica, tanto que en algunos ordenamientos jurídicos como el francés, la oposición a su admisión fue vehemente y se constituyó en uno de los motivos para que la transposición de la directiva 85/374 tardara 10 años adicionales (Picod \& Davos, 2010, p. 236).

Se comprende por riesgo de desarrollo un defecto existente en el momento de la puesta en circulación del producto, pero imprevisible y no susceptible de ser conocido por el productor, debido al estado de la ciencia y la tecnología en el momento en que el producto fue puesto en el mercado (p. 243). La Corte Suprema de Justicia colombiana en sentencia del 30 de abril de 2009 declara:

Se entienden por tales aquellos peligros que un producto entraña en el momento en el que se introduce en el mercado, pero que, dado el estado de la ciencia y de la técnica no eran cognoscibles y, por ende, previsibles, por 
el fabricante. O, para decirlo de otro modo, acaece esa causal de inimputabilidad cuando, conforme a los dictados de la ciencia o de la técnica, entonces en vigor, el producto se consideraba inocuo, pero que posteriores investigaciones demuestran que es dañoso.

Con respecto a la aceptación de esta causal de exoneración se pueden encontrar dos posturas antagónicas; por un lado, la que tienen quienes la consideran inaceptable por la prevalencia del interés general en la medida en que con ella se impone la carga del riesgo a los consumidores, los que además no están en capacidad de asegurarlo (Lasarte, 2010, p. 294); por otro, la postura de quienes estiman que el productor debe responder por el riesgo de desarrollo, porque debe garantizarse la inocuidad de los productos que se lanzan al mercado masivo de consumo, además la óptica debe centrarse en el consumidor, quien padece de forma injusta el daño y no en el productor (Lorenzetti, 2009, p. 542).

Al respecto se pone de presente un obstáculo, que fallaría la "causalidad" según la teoría tradicional de la responsabilidad civil, por lo cual proponen algunos autores, prescindir de la teoría de la causalidad para darle prevalencia al criterio "riesgo/provecho", para que el productor responda en la proporción a la cuota del mercado, posición que resultaría más benéfica socialmente (Márquez \& Mosset de Espanés, 1995).

Por otra parte, encontramos la perspectiva de quienes defienden su inclusión como causal de exoneración de responsabilidad como modo de evitar ausencia de estímulo a la innovación a cargo de los productores, y hallan además su razón de ser en la propia "previsibilidad del daño”. Según Vela (2004) esta causal no está pensada solo para los dañados sino también en beneficio de la actividad empresarial, a la que no quiere coartar en su dimensión de investigación científica y técnica y, por supuesto, en la propia naturaleza de la responsabilidad objetiva que no puede ser absoluta (p. 106).
Siguiendo la misma línea de pensamiento, se ha dicho que los cambios operados después de la puesta en el mercado del producto, siempre que este estuviese ajustado a los parámetros de seguridad propios del momento en que se comercializó, no pueden generar responsabilidad alguna del fabricante, pues este actuó con diligencia según el estado de la técnica en ese momento (Larrosa, 2011, p. 223). Señala DíezPicazo (1999) sobre esta postura, que solo se puede responder por los defectos controlables, es decir, aquellos que previeron o se debieron prever, y que, por tanto, no debe haber responsabilidad por encima del nivel científico o tecnológico que existía cuando se fabricó el bien. Aunque este mismo autor, expresa que con ese argumento se estaría retornando parcialmente a criterios de responsabilidad por culpa, contrario a la responsabilidad objetiva, al establecerse un canon de diligencia, y además se rompería el principio de la indemnización del daño cuando se violan las expectativas de seguridad que debía suscitar un producto (p. 154).

En todo caso, se dice por la doctrina que la interpretación de esta causal de exoneración se predica debe ser estricta, no se trata del conocimiento personal del productor sino del estado objetivo de saberes a los cuales este podía acceder en el momento de la fabricación del producto (Picod \& Davos, 2010). El Tribunal de Justicia de las Comunidades Europeas en 1997 se pronunció sobre el artículo 4(e) del Consumer Protection Act inglés y su conformidad con la directiva europea, y sobre el contenido de la norma inglesa dijo que la expresión "el estado de los conocimientos científicos y técnicos" es objetivo porque se trata del conocimiento que se pueda esperar de un productor de productos análogos para la detención del defecto, además agregó que el conocimiento debe ser "accesible", lo que significa que un productor del mismo sector pueda tener acceso a la información en cuestión (Taylor, 1999, p. 73).

Cabe anotar que la directiva comunitaria europea permitió, con buen tino, a los Estados 
miembros excluir la aplicación de esta causal o restringirla, en España por ejemplo, según el artículo 140.3 del Texto refundido de la Ley General para la Defensa de Consumidores y Usuarios (conocido en España como el TRLGDCU), no se puede aducir esta causal de exoneración en el caso de medicamentos, alimentos o productos destinados al consumo humano; mientras que en Francia no se aplica esta causal si el daño ha sido motivado por "un elemento del cuerpo humano o por los productos derivados de este", y en Inglaterra igualmente no es posible alegar si el daño ha sido causado por un elemento del cuerpo humano o por productos derivados de este.

En síntesis, podemos afirmar que la ley 1480 de 2011 asumió la posición más generosa para el productor al consagrar el riesgo de desarrollo como causal de exoneración de la responsabilidad, sin condicionar su aplicabilidad ni imponer exclusiones de algún tipo. Para evitar caer en simplismos, se aclara que el tema específico de los riesgos de desarrollo ha generado un extenso debate que merece revisarse y analizarse más minuciosamente, pero que supera los límites de este escrito.

\section{Conclusiones}

La responsabilidad por producto defectuoso tiene antecedentes en la jurisprudencia del derecho anglosajón, sobre todo los pronunciamientos de los jueces norteamericanos que con sabiduría supieron responder a los desafíos del contexto de la industrialización para concebir un régimen de responsabilidad especial, que implica la superación del principio caveat emptor y aquel de la relatividad de los actos jurídicos.

El tema tiene una normativa reciente en Colombia a través de la ley 1480 de 2011, la cual reguló la materia de manera concreta por primera vez, dado que el decreto 3466 de 1982 tenía una reglamentación deficiente y poco precisa sobre el asunto. No obstante los pronunciamientos de la Corte Suprema de Justicia y la Corte Constitucional, basadas en doctrina y legislación extranjera, delimitaron los alcances de esta especie de responsabilidad en el contexto colombiano. La reciente norma nacional revela una gran influencia del régimen comunitario europeo, a pesar de que presenta algunas diferencias frente al mismo.

La responsabilidad por producto defectuoso forma parte del deber de seguridad que tienen a su cargo los productores y proveedores en el mercado. Este deber de seguridad se manifiesta de dos maneras en el derecho del consumo: mediante un régimen preventivo de carácter prevalentemente administrativo de control de calidad, idoneidad y seguridad de los bienes que circulan en el mercado; y por medio de un régimen de responsabilidad por productos defectuosos.

La responsabilidad por producto defectuoso tiene tres atributos en el derecho colombiano: es un régimen de responsabilidad especial -"responsabilidad de mercado"-, es responsabilidad solidaria y es responsabilidad objetiva. Estas características la alejan del régimen antiguo de responsabilidad civil, para convertir esta subespecie de responsabilidad en un régimen de avanzada, propio para afrontar las dificultades de las economías de mercado.

Las definiciones de "seguridad" y "producto defectuoso", contempladas en la ley 1480 de 2011, evidencian deficiencias y cierto grado de incoherencia. La noción de producto defectuoso se centra en la idea de "error" y no en la de "seguridad" y en específico, aquella que razonablemente se espera de un producto en el mercado.

La responsabilidad por producto defectuoso se aplica según la norma colombiana a daños ocasionados por bienes y servicios, al contrario de otros ordenamientos jurídicos donde tienen tratamiento diferencial. Así mismo, son responsables solidariamente productor $\mathrm{y}$ 
proveedor, mientras que en el régimen europeo el proveedor (suministrador) solo es responsable subsidiariamente.

Según la ley colombiana para configurar esta especie de responsabilidad, el consumidor debe probar el daño, el defecto y el nexo causal. Frente a estos dos últimos, en algunos eventos se evidencia dificultad probatoria, dada la posición de inferioridad del consumidor. $\mathrm{La}$ carga dinámica de la prueba que se consigna en el Código General del Proceso, permitirá a los jueces solucionar esta dificultad a favor de los consumidores.

Las causales de exoneración de la responsabilidad por productos defectuosos contempladas en la ley 1480 de 2011 son amplias y generosas con el productor, en la medida en que se acogieron sin cortapisa alguna las causales admitidas con restricciones en el derecho comparado. Esta apreciación se hace más clara en la admisión de los "riesgos de desarrollo" como eximente de responsabilidad sin limitaciones particulares.

Sin duda alguna, la jurisprudencia de las altas cortes colombianas desempeñará un papel importante en la fijación de los alcances y la corrección de las incoherencias y defectos que padece la ley 1480 de 2011 en la materia.

\section{Notas}

\begin{abstract}
${ }^{1}$ Nótese que el numeral 8 del artículo 5 define como producto todo bien o servicio, pero la ley no hace exclusión alguna de su cobertura y aplicación para alguna clase de bienes en especial, y por el contrario regula el tema de la garantía de los inmuebles (art. 8).
\end{abstract}

\section{Referencias}

Acedo, A. (2012). Derecho de Consumo. Madrid: Dykinson.

Barrientos, F. (2010). La responsabilidad civil del fabricante bajo el artículo 23 de la Ley de Protección de los Derechos de los Consumidores y su relación con la responsabilidad civil del vendedor. Revista Chilena de Derecho Privado, 14, 109-158.

Beck, U. (2006). La sociedad del riesgo: hacia una nueva modernidad. Barcelona: Paidós.

Borghetti, J. S. (2004). La responsabilité du fait des produits, étude de droit comparé. Paris: LGDJ.

Bruselas. Directiva 374 de 1985 . Relativa a la aproximación de las disposiciones legales, reglamentarias y administrativas de los Estados Miembros en materia de responsabilidad por los daños causados por productos defectuosos. Diario Oficial DO L 210. Consejo de las Comunidades Europeas, julio de 1985.

Bruselas. Directiva 95 de 2001. Relativa a la seguridad general de los productos. Diario Oficial L 11. Parlamento Europeo y Consejo de las Comunidades Europeas, diciembre de 2001.

Bruselas. Reglamento 765 de 2008. Por el que se establecen los requisitos de acreditación y vigilancia del mercado relativos a la comercialización de los productos y por el que se deroga el Reglamento (CEE) no 339/93. Diario oficial L 218. Parlamento Europeo y Consejo de las Comunidades Europeas, julio de 2008.

Calais-Auloy, J., \& Steinmetz, F. (2006). Droit de la Consommation. Paris : Dalloz.

Cillero, P. (2000). La responsabilidad civil del suministrador final por daños ocasionados por productos defectuosos. Madrid: Civitas.

Coderch, P., Piñero, J., \& Rubí, A. (2003). Responsabilidad civil del fabricante y teo- 
ría general de la aplicación del derecho (Lawenforcement) (Working paper $\mathrm{n}^{\circ}$ 164). Universitat Pompeu Fabra.

Coleman, J. L. (2010). Riesgos y daños. Madrid: Marcial Pons.

Constitución Política (1991). Congreso de la República de Colombia. Colombia.

Costa, C. (1998). Responsabilidade civil do fabricante por produto defeituoso na União Europeia e no Brasil. Revista de administração publica, 32(3), 249-255.

Decreto 3466 de 1982. Por el cual se dictan normas relativas a la idoneidad, la calidad, las garantías, las marcas, las leyendas, las propagandas y la fijación pública de precios de bienes y servicios, la responsabilidad de sus productores, expendedores y proveedores, y se dictan otras disposiciones. Diario Oficial No. 33.559. Presidencia de la República, diciembre de 1982.

Díez-Picazo, Luis. (1999). Derecho de Daños. Madrid: Civitas.

Estados Unidos de América. Gladys Escola vs. Coca Cola bottling Company de Fresno. (1994, julio 05). Apelación. Corte Suprema de California.

Farina, J. (2009). Defensa del consumidor y del usuario. Argentina: Editorial Astrea.

Ghestin, J. (Ed.). (1987). La directive communautaire et son introduction en droit francais. En Securité des Consommateurs et responsabilité du fait des produits défectueux. París: LGDJ.

Giraldo, A., Caycedo, C., \& Madriñan, E. (2012). Comentarios al nuevo estatuto del consumidor. Bogotá: Legis.

Gutiérrez, P. (2011). El concepto legal de "defecto" en el régimen español y europeo de responsabilidad civil por daños causados por productos defectuosos. En Responsabilidad civil, derecho de seguros y filosofía del derecho (Tomo I) (p. 657- 706). Bogotá: Biblioteca Jurídica Diké.

Hernández, C. A., \& Frustragli, S. A. (2010). El funcionamiento de las eximentes en supuestos de daños al consumidor. Trabajos del Centro, 8, 1-16. Recuperado de http:// revista.cideci.org/index.php/trabajos/article/view/98/135

Herrera, R. (2007). La responsabilidad derivada de los daños producidos por la biotecnología. Madrid: Reus.

Hinestrosa, F. (2003). Responsabilidad por productos defectuosos. En Derecho Económico (Tomo IV, Colección Enrique LowMurtra) (pp. 326-346). Bogotá: Universidad Externado de Colombia.

Lasarte, C. (2010). Manual de protección de los consumidores y usuarios. Madrid: Dykinson.

Larrosa, M. (2011). Derecho de Consumo, protección legal al consumidor. Madrid: El Derecho editores.

Ley 1480 de 2011. Por medio de la cual se expide el Estatuto del Consumidor y se dictan otras disposiciones. Diario oficial No. 48.220. Congreso de la República, octubre de 2011.

Ley 1564 de 2012. Por medio de la cual se expide el Código General del Proceso y se dictan otras disposiciones. Diario Oficial No. 48.489. Congreso de la República, julio de 2012 .

Lorenzetti, R. (2009). Consumidores. Buenos Aires: Rubinzal Culzoni Editores.

Márquez, J. F., \& Moisset de Espanés, L. (1995). Riesgos de desarrollo. Recupera- 
do de http://www.acaderc.org.ar/doctrina/ articulos/riesgos-de-desarrollo

Martín, C., \& Solé, F. (2005). Responsabilidad civil por productos defectuosos. En M. Reyes (Coord.), Derecho Privado de Consumo (157-195). Valencia: Tirant Lo Blanch.

McPherson vs. Buick Motor (1916, marzo 14). Apelación 217 NY 382. Corte de Apelaciones de Nueva York.

Monroy, M. (2010). Las garantías en la venta de productos de consumo. Protección jurídica del Consumidor en el derecho colombiano (Academia Colombiana de Jurisprudencia). Recuperado de http:// www.acj.or.g.co/o/sist_info/index.php?p $=$ productsMore $\&$ iProduct $=1377$

Mosset, J., \& Wajntraub, J. (2008). Ley de defensa del Consumidor, Buenos Aires: Rubinzal Culzoni Editores.

Munar, P. O. (2013). La responsabilidad por productos, los grandes hitos de su evolución. En J. M. Gual \& J. C. Villalba (Dirs.), Derecho del Consumo. Problemáticas actuales (pp. 173-212). Bogotá: Editorial Ibañez.

Namen, J. (2007). Reglas específicas de responsabilidad por productos defectuosos en Colombia. Revista e-Mercatoria, 6(1), $1-32$.

Owen, D., Madden, S., \& Davis, M. (2000). Madden \& Owen on products liability. Estados Unidos: West Group.

Paniagua, M. (2012). La responsabilidad civil por daños y perjuicios causados por bienes o servicios defectuosos. En L. Miranda \& J. Pagador (Coords.), Derecho Privado de los Consumidores (pp. 291-342). Madrid: Marcial Pons.
Parra, M. (1990). Daños por productos y protección al consumidor. Barcelona: José María Bosch Editor.

Parra, M. (2002). Responsabilidad civil por productos y servicios defectuosos. Responsabilidad civil del fabricante y de los profesionales. En L. Reglero-Campos (Coord.), Lecciones de Responsabilidad civil (pp. 457-504). Navarra: Aranzadi.

Picod, Y., \& Davos, H. (2010). Droit de la Consommation. París: Sirey.

Pipaon, G. (2010). Derecho de los consumidores y usuarios. Valladolid: Lex Nova.

Reino de España. Real Decreto legislativo 1 de 2007. Por el que se aprueba el texto refundido de la Ley General para la Defensa de los Consumidores y Usuarios y otras leyes complementarias. BOE No. 287. Ministerio de la Presidencia, noviembre de 2007.

República Argentina. Hugo Arnaldo mosca vs. Provincia de buenos Aires (Policia Bonaerense) y otros. (2007, marzo 06). Demanda. Corte Suprema de Justicia de la Nación.

República Argentina. María Ledesma vs. Metrovías S.A. (2008, abril 22). Recurso de Hecho. Corte Suprema de Justicia de la Nación.

República del Perú. Ley 29517 de 2010. Código de Protección y Defensa del Consumidor. Congreso de la República, agosto de 2010.

República Federativa de Brasil. Ley Federal 8078 de 1990. Código de Defensa del Consumidor. Dispone sobre la protección del consumidor y dicta otras providencias. Congreso nacional, septiembre de 1990. 
Resolución 60220 de 2012. Por la cual se da una orden preventiva de suspensión de producción y comercialización de un producto y se realizan advertencias al consumidor para evitar que se cause daño con su uso. Superintendencia de Industria y Comercio, octubre de 2012.

Reyes, M. J. (2009). Manual de Derecho privado de consumo. Madrid: La ley.

Ruíz, C., \& Marín, I. (2006). Producto inseguro y producto defectuoso. InDret revista para el análisis del derecho, 388, 1-20. Recuperado de http://www.indret.com/ pdf $/ 388$ _es.pdf

Sentencia C-1141 (2000, agosto 30). Acción de Inconstitucionalidad. M.P. Eduardo Cifuentes Muñoz, Corte Constitucional.

Sentencia C-973 (2002, noviembre 13). Acción de Inconstitucionalidad. M.P. Álvaro Tafur Galvis, Corte Constitucional.

Sentencia del 30 de abril de 2009. Exp. 258993193-992-1999-00629-01. M.P. Pedro Octavio Munar Cadena. Corte Suprema de Justicia, Sala de Casación Civil.

Sentencia del 24 de septiembre de 2009. Exp. 05360-31-03-001-2005-00060-01. M.P. César Julio Valencia Copete. Corte Suprema de Justicia, Sala de Casación Civil

Stiglitz, G., \& Bru, J. (2009). Régimen de la responsabilidad civil por daños al consumidor. En D. Rusconi (Coord.), Manual de Derecho del Consumidor (pp. 389449). Buenos Aires: Abeledo Perrot.
Tamayo, J. (1998). La responsabilidad civil por productos defectuosos y su aseguramiento. Revista Ibero-latinoamericana de seguros, 12, pp. 7-87.

Tamayo, J. (2007). La responsabilidad civil por productos defectuosos y su aseguramiento. En Responsabilidad Civil y del Estado, Instituto Antioqueño de responsabilidad Civil y del Estado. Medellín: Librería Jurídica Sánchez.

Taylor, S. (1999). L'harmonisation communautaire de la responsabilité du fait des produits défectueux. Paris: LGDJ.

Vela, A. J. (2004). Criterios de aplicación del régimen de responsabilidad civil por productos defectuosos. Granada: Editorial Comares.

Villalba, J. (2012). Introducción al derecho del consumo. Bogotá: Universidad Militar Nueva Granada.

Weingarten, C. (2007). Derecho del Consumidor. Buenos Aires: Editorial Universidad SRL.

Woolcott, O. (2007a). La naturaleza de la responsabilidad del productor a la luz del derecho norteamericano. Prolegómenos Derechos y Valores, 10(19), 125-148.

Woolcott, O. (2007b). La responsabilidad del productor. Bogotá: Editorial Ibañez.

Woolcott, O. (2009). Causalidad y daño por productos defectuosos a propósito de los casos DES en los Estados Unidos. Revista IUSTA, 30, 109-130. 
